\title{
A interação e apropriação tecnológica de pessoas com deficiência através de ferramenta multimídia acessí- vel
}

\author{
The interaction and technological appropriation of people with disabilities through \\ accessible multimedia tool
}

\author{
Lourenço de Oliveira Basso \\ NIEE/UFRGS \\ Porto Alegre, Av. Paulo Gama, 110, \\ prédio 12201, sala 802 . \\ 1.oliveirabasso@gmail.com
}

\author{
Lucila Maria Costi Santarosa \\ NIEE/UFRGS \\ Porto Alegre, Av. Paulo Gama, 110, \\ prédio 12201, sala 802 . \\ lucila.santarosa@ufrgs.br
}

\author{
Débora Conforto \\ NIEE/UFRGS \\ Porto Alegre, Av. Paulo Gama, 110, \\ prédio 12201, sala 802 . \\ deboraconforto@gmail.com
}

\begin{abstract}
Resumo Diante de um contexto em que a evolução tecnológica amplia as formas de disseminação e acesso à informação, explorando o uso da multimídia e a mescla dos diferentes tipos de linguagens, percebe-se que pessoas com deficiência ainda permanecem excluidas dos processos de produção e recepção de dados digitais. Diante do potencial das Tecnologias da Informação e Comunicação (TIC) para firmarem-se como opção para a superação de barreiras, apresenta-se aqui o desenvolvimento de uma ferramenta, denominada Oficina Multimídia, que visa a propiciar a interação desses indivíduos e a expressão de suas ideias em processos de autoria e trabalho em grupo, mediante o uso de signos audiveis, imagéticos e verbais. Por meio de um estudo qualitativo junto a sujeitos com diferentes necessidades especiais (deficientes visuais, deficientes motores e portadores de Sindrome de Down), investigou-se de que forma a implementação do software, seguindo recomendações de acessibilidade e a disponibilização de recursos para facilitação do uso por pessoas com deficiência na produção multimídia, favorece os processos de apropriação tecnológica e de interação entre os pesquisados. Verificou-se a pertinência da aplicação de testes com usuários finais para detecção de melhorias e validação de certas estratégias para adoção em projetos futuros de ferramentas acessiveis. Complementarmente, foram realizados testes de compatibilidade da Oficina Multimídia com um protótipo de tablet e suas tecnologias assistivas disponíveis. O potencial da ampliação de espaços infoinclusivos para expressão de pessoas com as mais distintas características pode ser observado nas produções elaboradas pelos grupos validadores.
\end{abstract}

Palavras-Chave: Inclusão sociodigital; Acessibilidade; Multimidia, Interação; Desenvolvimento cognitivo; Apropriação

\footnotetext{
Abstract Against a broad context of increased technological development, profuse forms of information dissemination and access by means of multimedia resources and multiple languages, it can be observed that people with special needs are still excluded from processes of digital data production and reception. Considering the potential of Information and Communication Technologies (ICT) to provide an alternative of transposing social limitations, this study introduces a tool
} 
labeled Oficina Multimidia, which aims at promoting the social interaction and manifestation of ideas by such individuals in processes of authorship and team work involving aural, imagetic and verbal signs. A qualitative investigation was conducted among participants with distinct needs (visually impaired individuals, physically handicapped and individuals with Down syndrome) to evaluate the extent to which the software implementation, following recommendations regarding the accessibility and availability of multimedia resources for PSNs, facilitates processes of technological appropriation and interaction among the research participants. Tests carried out with the software users validated part of the strategies adopted and pointed out to the need of considering improvements for future projects involving similar multimedia access tools. Complementarily, tests were conducted to evaluate the compatibility of Oficina Multimidia with a tablet prototype and its available assistive technologies. The potential of infoinclusive environments to extend the socio-digital participation of individuals with disabilities can be observed in the assignments produced by the group of participants validating the project.

Keywords: Socio-digital inclusion; Accessibility; Multimedia, Interaction; Cognitive development; Technological appropriation.

Recebido: 25 de Junho de 2013 / Aceito: 28 Dezembro de 2013

DOI: 10.5753/RBIE.2013.21.03.12 


\section{Introdução}

A informação tem se constituído em um bem cuja valorização vem crescendo sob influência das inovações tecnológicas. Ampliam-se as formas de disponibilização das informações, bem como as maneiras através das quais as pessoas com elas interagem. A cada dia, surgem novas formas de acessá-las, de processá-las, de compartilhá-las, o que ocasiona forte impacto no comportamento e nas relações humanas.

A mescla nas formas de apresentação das informações é um dos aspectos influentes nesse processo de mudança decorrente da evolução tecnológica. Signos audíveis, imagéticos e verbais não são mais vistos apenas como unidades isoladas, passando a conviver e misturar-se cada vez mais em uma única linguagem, processo este referido por Santaella [16] como "hibridização". Adicionalmente, alteram-se as formas de acessar essa linguagem. Os caminhos no percurso através da informação não necessitam ser obrigatoriamente lineares, sequenciais. A interligação das informações e sua disponibilização em rede permitem que os indivíduos tenham maior liberdade nas escolhas das trilhas a serem traçadas. Todas estas alterações afetam diretamente a postura do receptor nesse novo contexto, o qual tem a possibilidade de assumir um papel muito mais ativo do que aquele descrito nos modelos tradicionais da comunicação.

Dentro do contexto da utilização das novas tecnologias, em especial do uso do computador em rede para propiciar comportamentos mais participativos dos indivíduos envolvidos em processos interativos, destacam-se os recursos para desenvolvimento de produções textuais ou multimídia de forma coletiva. Apresentam-se atualmente disponíveis diversos softwares para autoria realizada em grupo, os quais permitem explorar dimensões presentes nos processos de interação tais como negociações, reflexão sobre opiniões contrárias, aceitação de críticas, respeito mútuo, além de aspectos relacionados mais diretamente ao processo de autoria: coleta de dados, formulação de intenções, planejamento e revisão de metas [2].

Além das dimensões acima referidas, é importante destacar o papel assumido pela interação no desenvolvimento dos indivíduos. Sob este ponto de vista, apresentase como fundamental o aporte da teoria sociointeracionista de Vygotsky, através da qual são estudadas as formas como os seres humanos desenvolvem os mecanismos intencionais, as ações conscientemente controladas que os diferenciam dos demais seres vivos. Vygotsky [23] aponta o papel fundamental da interação entre indivíduos com diferentes níveis de desenvolvimento.

Nesse sentido, os avanços dos recursos tecnológicos apresentam-se como pontos de potencialização desses processos de interação. Dentre os grupos beneficiados pelo progresso das tecnologias, destacam-se as pessoas com deficiência, as quais fazem uso, muitas vezes, de softwares ou hardwares para suprimir algum tipo específico de limitação física ou cognitiva, participando ativamente de interações com outros sujeitos e com as informações disponibilizadas em nossa sociedade. Portanto, para que seja propiciada a inclusão desses indivíduos, torna-se imprescindível o respeito aos aspectos relacionados à acessibilidade das tecnologias e das informações.

Apesar das crescentes iniciativas no sentido de expandir a inclusão digital a todo cidadão, este processo ainda ocorre de forma muito tímida. Um importante indicativo da necessidade de avanço nessa área pode ser observado justamente na carência de recursos acessíveis para o desenvolvimento de produções multimídias coletivamente. A observação dessa necessidade motivou o desenvolvimento do presente estudo.

Investiga-se, portanto, de que forma a implementação e a utilização de uma ferramenta acessível para a produção de documentos multimídia pode vir a favorecer os processos de apropriação tecnológica e de interação de pessoas com deficiência.

Para tanto, o presente trabalho apresenta a construção do referido recurso tecnológico, devidamente integrado ao AVA Eduquito, e focaliza no processo de sua validação junto a sujeitos com deficiência, mediante a observação da ocorrência de processos de interação e de apropriação tecnológica no decorrer da produção individual ou coletiva de documentos multimídia.

\section{Recursos de autoria como foco de investigações}

Encontram-se disponíveis, atualmente, inúmeras pesquisas relacionadas à área da produção coletiva de materiais multimídia mediada pelo uso do computador. A crescente utilização da Tecnologia de Informação e Comunicação (TIC) pode ser destacada como fator influente no aumento do interesse pela produção realizada através de "múltiplas mãos", utilizando o computador como instrumento.

Dentro do Programa de Pós-Graduação em Informática na Educação (PPGIE) da Universidade Federal do Rio Grande do Sul (UFRGS), foram desenvolvidos alguns trabalhos com o objetivo de implementar editores de textos coletivos. Dá-se destaque aqui a dois softwares: o Equitext e o Editor de Texto Coletivo (ETC). 
O ETC teve seu desenvolvimento iniciado no final de 2001 pelo NUTED (Núcleo de Tecnologia Digital aplicada à Educação) - da Faculdade de Educação da Universidade Federal do Rio Grande do Sul. Esse editor tem como objetivo propiciar a escrita coletiva/cooperativa através da rede, fazendo parte de um projeto maior denominado ROODA (Rede cOOperativa de Aprendizagem), que visa ao desenvolvimento de ambientes virtuais de aprendizagem [5].

Desenvolvido por alunos e bolsistas do PPGIE da UFRGS, o Equitext apresenta-se como outra opção de ferramenta para escrita colaborativa. No Equitext, após o cadastramento dos integrantes, estes podem criar parágrafos, apagá-los, editá-los e trocar sua ordem. Assim, é preciso que a cooperação entre os indivíduos funcione para que a texto final tenha certa coerência e apresente um resultado interessante [1].

Podem ser destacadas ainda, como ferramentas de escrita coletiva, a variedade de sistemas Wiki disponíveis atualmente na Internet, tais como os baseados no MediaWiki $^{1}$ e no Twiki ${ }^{2}$. Schäfer et. al. [21] apontam que nesses sistemas a autoria pode ser coletiva, ou seja, os participantes podem alterar as postagens uns dos outros, mas também pode ser individual em se tratando dos comentários (ou discussões), nos quais não é possível escrever de forma compartilhada. Dentre as características desses sistemas, Primo et. al. [14] enfatizam que a alteração dos conteúdos é realizada através do uso de uma sintaxe simplificada que não exige de seus usuários conhecimentos específicos de programação web ou de formatação Wiki. Os sistemas Wiki também introduzem uma interessante forma de criação automatizada de links para páginas internas ao sistema, os quais direcionam para tópicos que, se ainda não foram criados, convidam o usuário a ser o primeiro colaborador no desenvolvimento desse conteúdo. Nesses sistemas é importante enfatizar que "cada conceito referido em alguma das páginas pode ser refinado e detalhado pelos que realizam a leitura agora não mais de forma passiva, mas ativamente contribuindo, corrigindo, completando." [9].

O Google Docs apresenta-se como uma das poucas ferramentas para escrita coletiva cuja adição pode ser realizada sincronamente, ou seja, as alterações realizadas por um indivíduo são replicadas automaticamente na tela dos demais participantes que compartilham o documento criado. Essa ferramenta simula a criação e utilização de documentos nos formatos popularizados pelo Microsoft Office, apresentando inclusive compatibilidade com tais

${ }^{1}$ A enciclopédia on-line Wikipédia é construída usando o MediaWiki. Mais detalhes sobre o projeto MediWiki podem ser encontrados no website http://www.mediawiki.org/ .

${ }^{2}$ Mais detalhes sobre o projeto TWiki podem ser encontrados no website http://twiki.org/ . arquivos, explorando o conceito de cloud computing ${ }^{3}$ (computação nas nuvens).

Além das ferramentas para a construção coletiva de textos, destacam-se neste trabalho algumas propostas que oferecem espaço para a criação, ainda que de forma individual, de histórias (em quadrinhos ou em formato de livros digitais). Esses softwares oferecem recursos que propiciam a escrita de um sistema narrativo em um formato que alia a utilização de dois códigos de signos gráficos, a imagem e a linguagem escrita, possibilitando a elaboração de materiais que estimulam no leitor o desenvolvimento da criatividade e a capacidade de abstração, além de "fornecer subsídios para o desenvolvimento da capacidade de análise, interpretação e reflexão" [6].

Dentre as ferramentas que se enquadram nesta categoria, destaca-se o Fábrica Fantástica [17], desenvolvido pelo Núcleo de Informática na Educação Especial (NIEE/UFRGS) e que usa a metáfora de uma "fábrica", estimulando (através de um personagem) a criança a trabalhar no desenvolvimento de atividades que envolvem a realização de tarefas lúdicas, no âmbito do progresso de dimensões cognitivas. Dentro desse sistema, apresenta-se com especial relevância para o presente trabalho uma ferramenta chamada "Editor de Histórias", em que o grafismo e a escrita se revelam recursos expressivos, oportunizando ao usuário alternativas para o desenvolvimento do seu potencial na área da criação textual, realizadas, porém, de forma individual. Na opção de "Confecção de Páginas", o usuário recebe orientações para produzir páginas de sua história.

Outra ferramenta que pode ser apontada chama-se Hagaquê [15], um editor de histórias em quadrinhos que possibilita a criação com personagens, cenários e sons escolhidos ou gravados pelo usuário. Além de disponibilizar esses recursos, o software, que funciona como um aplicativo executado no computador do usuário, possibilita a publicação das histórias na Internet. O Hagaquê foi desenvolvido pelo Núcleo de Informática Aplicada à Educação (NIED) da UNICAMP.

Além dos softwares gratuitos para a construção de histórias, como os citados anteriormente, existem também opções comerciais disponíveis. Dentre elas, podemos citar o software Quadrinhos da Turma da Mônica ${ }^{4}$ e o Comic Life ${ }^{5}$, ambos disponíveis de forma gratuita apenas para testes pelo usuário. No Comic Life são disponibilizados modelos de estrutura da página, imagens que po-

\footnotetext{
${ }^{3}$ Uso dos recursos (memória, capacidades de armazenamento, processamento, etc) de servidores compartilhados e interligados por meio da Internet.

${ }^{4}$ Disponível em: <http://www.monica.com.br/software/quadrinh.htm>. Acesso em: 10 fev. 2010.

5 Disponível em: <http://plasq.com/comiclife>. Acesso em: $10 \mathrm{fev}$. 2010.
} 
dem ser inseridas na produção e caixas de textos que podem ser associadas aos recursos imagéticos.

Tomando-se como base a análise das aplicações acima citadas, elaborou-se um quadro comparativo onde é apresentado um resumo referente aos principais aspectos relevantes para a presente pesquisa. Dentre estes aspectos, ressaltamos a plataforma na qual a ferramenta é ofertada, visto que recursos desenvolvidos para a Web apresentam maior facilidade de integração com ambientes

\begin{tabular}{|c|c|c|c|c|c|c|c|}
\hline $\begin{array}{c}\text { Nome da } \\
\text { ferramenta }\end{array}$ & $\begin{array}{c}\text { Tipo de } \\
\text { plataforma }\end{array}$ & $\begin{array}{l}\text { Tipo de } \\
\text { produção } \\
\text { coletiva } \\
\text { permitida }\end{array}$ & $\begin{array}{c}\text { Pode ser } \\
\text { considerado } \\
\text { acessível }{ }^{1} \text { ? }\end{array}$ & $\begin{array}{l}\text { Permite } \\
\text { uso de } \\
\text { distintas } \\
\text { mídias? }\end{array}$ & $\begin{array}{c}\text { Permite } \\
\text { distribuir } \\
\text { mídias } \\
\text { livremente }\end{array}$ & $\begin{array}{c}\text { Apresenta } \\
\text { ferramentas } \\
\text { de comunica- } \\
\text { ção? }\end{array}$ & $\begin{array}{c}\text { O acesso } \\
\text { é gratui- } \\
\text { to? }\end{array}$ \\
\hline \multicolumn{8}{|c|}{ Programas de escrita coletiva } \\
\hline Equitext & Web & Assíncrona & Parcialmente & $\begin{array}{l}\text { Somente } \\
\text { imagens }\end{array}$ & Não & Não & $\begin{array}{l}\text { Somente } \\
\text { no servi- } \\
\text { dor ofi- } \\
\text { cial }\end{array}$ \\
\hline ETC & Web & Assíncrona & Parcialmente & $\begin{array}{l}\text { Somente } \\
\text { imagens }\end{array}$ & Não & $\begin{array}{l}\text { Sim: comuni- } \\
\text { cador ins- } \\
\text { tantâneo, e- } \\
\text { mail e fórum }\end{array}$ & $\begin{array}{l}\text { Somente } \\
\text { no servi- } \\
\text { dor ofi- } \\
\text { cial }\end{array}$ \\
\hline Wikipedia & Web & Assíncrona & Parcialmente & $\begin{array}{l}\text { Somente } \\
\text { imagens }\end{array}$ & Não & Não & $\mathrm{Sim}^{2}$ \\
\hline $\begin{array}{l}\text { Google } \\
\text { Docs }\end{array}$ & Web & Síncrono & Parcialmente & $\begin{array}{l}\text { Permite } \\
\text { uso de } \\
\text { imagens e } \\
\text { vídeos }\end{array}$ & Sim & $\begin{array}{l}\text { Sim: e-mail } \\
\text { (não inte- } \\
\text { grado) }\end{array}$ & $\begin{array}{l}\text { Somente } \\
\text { no servi- } \\
\text { dor ofi- } \\
\text { cial }\end{array}$ \\
\hline \multicolumn{8}{|c|}{ Programas para criação de histórias em quadrinhos } \\
\hline $\begin{array}{l}\text { Fábrica } \\
\text { Fantástica }\end{array}$ & $\begin{array}{l}\text { Aplicativo } \\
\text { local }\end{array}$ & $\begin{array}{l}\text { Não permi- } \\
\text { tido }\end{array}$ & Parcialmente & $\begin{array}{l}\text { Somente } \\
\text { imagens }\end{array}$ & Sim & Não & Sim \\
\hline Hagaquê & $\begin{array}{l}\text { Aplicativo } \\
\text { local }\end{array}$ & $\begin{array}{l}\text { Não permi- } \\
\text { tido }\end{array}$ & $\begin{array}{l}\text { Sim, sendo } \\
\text { inclusive } \\
\text { compativel } \\
\text { com leitor } \\
\text { de tela }\end{array}$ & $\begin{array}{l}\text { Permite } \\
\text { uso de } \\
\text { imagens, } \\
\text { sons e } \\
\text { vídeos }\end{array}$ & Sim & Não & Sim \\
\hline Comic Life & $\begin{array}{l}\text { Aplicativo } \\
\text { local }\end{array}$ & $\begin{array}{l}\text { Não permi- } \\
\text { tido }\end{array}$ & Parcialmente & $\begin{array}{l}\text { Permite } \\
\text { uso de } \\
\text { imagens, } \\
\text { sons e } \\
\text { vídeos }\end{array}$ & Sim & Não & $\begin{array}{l}\text { Somente } \\
\text { para } \\
\text { testes }\end{array}$ \\
\hline
\end{tabular}

Tabela 1: Quadro comparativo das ferramentas analisadas. disponíveis na Internet. A acessibilidade destes softwares, bem como a utilização de distintas mídias também foram observadas, tendo em vista a importância destes aspectos para o uso por pessoas com deficiência. A apresentação de recursos de comunicação integrados ao sistema foi analisada a fim de verificar o potencial de interação entre sujeitos no desenvolvimento de trabalhos coletivos. Por fim, analisou-se a disponibilidade gratuita ou não do recurso. 
Percebe-se que, com a evolução das tecnologias, passa a ser ofertado um conjunto cada vez maior de opções para o desenvolvimento de atividades coletivas ou realizadas com o uso de recursos hipermidiáticos. A importância da exploração de recursos que promovam a interação e o trabalho em grupo com pessoas com deficiência tem sido evidenciada em diversos estudos relacionados ao tema da aplicação da informática na educação especial. Algumas investigações dessa temática foram realizadas por integrantes do Núcleo de Informática na Educação Especial, sendo possível acompanhar no site ${ }^{1}$ do núcleo vários trabalhos coletivos desenvolvidos por alunos através da produção colaborativa de histórias, poesias, textos ilustrados com imagens, desafios, entre outros. Todos os materiais foram produzidos utilizando ferramentas de comunicação síncronas (chat e NetMeeting ${ }^{2}$ ) e assíncronas (correio eletrônico), disponíveis naquele dado momento, visto que não eram difundidos recursos que agregassem em um único contexto todas as funcionalidades necessárias para o desenvolvimento da produção coletiva.

Atualmente, a disponibilização desses recursos, com um conjunto cada vez mais amplo de funcionalidades, vem se tornando mais usual. No entanto, um dos aspectos primordiais para a utilização dos recursos tecnológicos por pessoas com deficiência continua não recebendo a devida importância: trata-se do respeito às questões de acessibilidade $^{3}$. Permitir que as pessoas, independentemente de suas características específicas, tenham plenas condições de participar de atividades de trabalho em grupo e com constante interação com seus pares apresenta-se como um fator fundamental para possibilitar o desenvolvimento social, afetivo e cognitivo desses sujeitos.

\section{Desenvolvimento do protótipo}

Como um dos objetivos previstos no desenvolvimento deste trabalho, foi planejada, para sua etapa inicial, a realização das fases de modelagem e implementação da Oficina Multimídia. Essa ferramenta tem como característica oferecer a flexibilidade necessária para que sejam criados materiais nos mais diferentes formatos: histórias, jornais, revistas, poesias, roteiros (teatro, filme, novela) ou histórias em quadrinhos. Essa dinâmica apresenta-se através da possibilidade de utilização de mídias (imagens,

\footnotetext{
${ }^{1}$ Disponível em: <http://www.ufrgs.br/niee/alunos.php>. Acesso em: 10 fev. 2012

2 Software de videoconferência de propriedade da Microsoft cujo desenvolvimento foi descontinuado.

${ }^{3}$ Os softwares Fábrica Fantástica e Hagaquê foram desenvolvidos respeitando diversos aspectos referentes à acessibilidade para pessoas com deficiência. No entanto, estas duas ferramentas não possibilitam o desenvolvimento de atividades coletivamente, o que reduz a exploração do potencial decorrente da interação desenvolvida no processo de produção em grupo.
}

vídeos, áudios) providas pela ferramenta, bem como materiais adicionais disponibilizados pelo próprio usuário. Dessa forma, o usuário tem total liberdade para desenvolver um documento multimídia explorando sua criatividade no processo de estruturação e composição do material, que pode ser construído de forma individual ou coletiva [18].

O protótipo da ferramenta foi desenvolvido baseandose na plataforma web, o que visa a reduzir os requisitos necessários para sua utilização (exigência apenas de computador com um browser e conexão com a internet) e a facilitar sua integração a Ambientes Virtuais de Aprendizagem (AVAs). Destaca-se o fato de que toda implementação desta investigação seguiu as recomendações de acessibilidade, tanto propostas pela WAI (W3C) através do Web Content Accessibility Guidelines (WCAG) 2.0 , quanto sugeridas por pesquisas ligadas à Informática na Educação Especial, tais como o trabalho desenvolvido por Sonza [22] sobre ambientes virtuais acessíveis a cegos.

Observando as diversas metodologias da engenharia de software, optou-se pela adoção da abordagem de métodos ágeis [7][10], para gerência e desenvolvimento da ferramenta. Embora existam metodologias tradicionais que possam ser mais facilmente absorvidas pelo grupo, a valorização humana (da equipe e dos usuários) e a flexibilidade promovida pelos métodos ágeis foram fatores determinantes para sua adoção no projeto.

Durante o processo de definição da interface da Oficina Multimídia, na busca pela adequação aos aspectos de usabilidade, realizaram-se testes com protótipos simulados em papel junto a usuários com problemas cognitivos e físicos. Os resultados destes testes, conforme destacado por Basso, Cheiran e Santarosa [4], apontaram para a necessidade de modificações no projeto inicial da ferramenta antes mesmo da implementação de algumas de suas funcionalidades, propiciando a otimização dos recursos humanos envolvidos e do tempo de desenvolvimento da ferramenta.

Apresenta-se, aqui, algumas informações sobre o resultado final obtido após a etapa de desenvolvimento da ferramenta Oficina Multimídia. Ressalta-se que esse recurso é apresentado devidamente integrado ao AVA Eduquito $^{4}$ e com suas demais ferramentas. A interface da Oficina Multimídia, conforme apresentado na figura 1, é dividida em 4 áreas: a) a barra de acessibilidade, b) os menus principais e secundários de funcionalidades, c) a área de conteúdo e d) o menu de navegação. $\mathrm{O}$ menu de navegação não é apresentado em todas as interfaces da ferramenta.

\footnotetext{
${ }^{4}$ Para um maior detalhamento sobre o ambiente Eduquito, recomendase a consulta ao trabalho de Santarosa e Basso [19].
} 


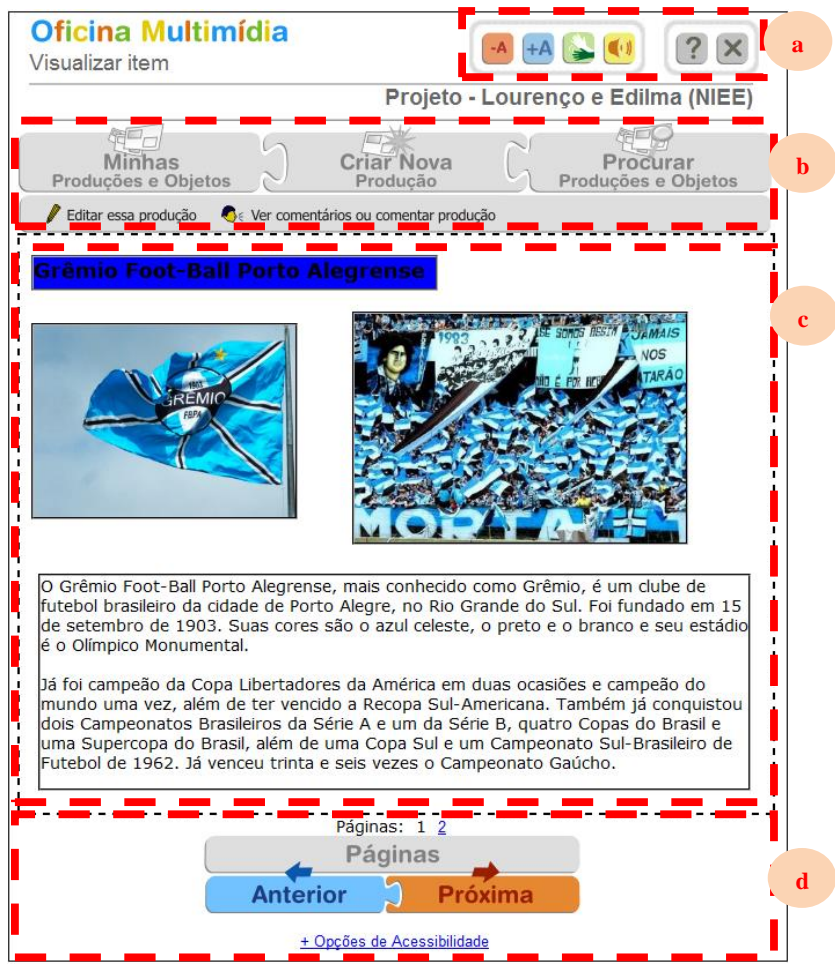

Figura 1 - Visualizar produção e áreas da interface

Alguns dos recursos de acessibilidade da Oficina Multimídia estão concentrados na área superior, na barra de acessibilidade. Sempre visível ao usuário e seguindo o padrão utilizado nas demais ferramentas do ambiente Eduquito, a barra de acessibilidade disponibiliza recursos que potencializam a interação da diversidade humana ao respeitar e valorizar especificidades sensórias e motoras. A implementação de funções de atalhos via teclado beneficia, especialmente, os usuários com defíciência visual que utilizam leitores de tela ou aqueles com deficiência motora, possibilitando acesso e deslocamento com maior agilidade entre as quatro diferentes áreas apresentadas na figura acima. As opções para diminuir ou aumentar fontes facilitam o uso do ambiente por pessoas com baixa visão. O link para um vídeo em Língua Brasileira de Sinais (LIBRAS) descreve as informações (de forma semelhante a um help) sobre a funcionalidade que está ativa. Além disso, apresenta-se a opção de acesso à ajuda em áudio, o qual apresenta o mesmo conteúdo comunicado no vídeo em LIBRAS. Essas estratégias facilitam a apropriação da funcionalidade da ferramenta por sujeitos com deficiência visual e auditiva.

$\mathrm{Na}$ interface de edição de produção, destacam-se as distintas formas que o redimensionamento e a distribuição espacial de um objeto pelo usuário podem ser realizados. A maneira tradicional é executada com o uso do mouse, clicando sobre a linha azul que contorna o objeto e arras- tando-o para alguma direção. Já para mover o objeto deve-se clicar sobre ele e arrastá-lo para o ponto desejado da produção. A outra forma de alterar o tamanho e a posição de um objeto é através da utilização do link "Opções de acessibilidade", que abrirá um formulário (Figura 2) onde serão carregadas - podendo ser alteradas - as seguintes informações do objeto selecionado: sua margem relativa à esquerda da produção, margem relativa ao topo, largura, altura e camada em que o objeto se encontra em relação aos demais objetos da produção. O referido formulário, assim como as demais interfaces do sistema, é apresentado de forma amplamente compatível com softwares leitores de tela, permitindo seu acesso também a pessoas com deficiência visual. O detalhamento sobre o espaço total disponível para a adequação das margens e dimensões dos objetos, bem como sobre o uso adequado das camadas de objetos encontra-se disponível no documento de ajuda do sistema, o qual é sensível ao contexto do usuário, ou seja, apresentará apenas informações referentes à interface na qual o usuário se encontra. Considera-se que algumas destas informações, tais como o espaço total disponível para posicionamento dos elementos, deveriam ser apresentadas já na própria interface para uma melhor compreensão dos usuários.

\begin{tabular}{|c|c|c|c|}
\hline \multicolumn{4}{|c|}{$\begin{array}{c}\text { Páginas: } 1 \underline{2} \\
\text { Páginas }\end{array}$} \\
\hline Anterior & Excluir & Criar Nova & Próxima \\
\hline & Nome do objeto: & Torcida & \\
\hline & Margem da direita: & 287 & \\
\hline & Margem do topo: & 66 & \\
\hline & Altura: & 198 & \\
\hline & Largura: & 286 & \\
\hline & Camada: & 1 & \\
\hline & & Aplicar alterações & \\
\hline & - Opções de & Acessibilidade & \\
\hline
\end{tabular}

Figura 2 - Opções de acessibilidade

Após a implementação da ferramenta Oficina Multimídia, realizou-se uma análise de seus recursos e sua interface tomando como base as definições contidas no WCAG 2.0. Os resultados desta análise da ferramenta frente aos quatro princípios de acessibilidade (perceptível, operável, compreensível e robusto), e de suas respectivas recomendações, apontam para um produto desenvolvido com uma profunda preocupação em respeitar os padrões que favorecem o acesso e interação de usuários com as mais distintas capacidades físicas, sensoriais ou intelectuais. Notou-se, no entanto, a possibilidade de execução de algumas melhorias ${ }^{1}$ para um completo atendimento das recomendações propostas pela WAI/W3C.

\footnotetext{
${ }^{1}$ Informações detalhadas sobre os resultados desta análise podem ser encontrados em Basso [3].
} 


\section{Validação da ferramenta}

A segunda etapa desta investigação contemplou a realização de um estudo empírico com pessoas com deficiência por meio da realização de atividades práticas utilizando a Oficina Multimídia, buscando observar os processos de interação e apropriação tecnológica dos usuários. Nesta etapa, realizou-se uma pesquisa qualitativa por meio de um estudo de caso com sujeitos de três grupos distintos de usuários: um grupo de jovens deficientes visuais (aqui identificados por SE, SC e SK), um grupo de jovens com Síndrome de Down (identificados por SL, $\mathrm{SB}$ e SF) e um grupo de senhores com deficiência física (identificados por SR e SJ).

No que se refere à fluência digital e características dos sujeitos investigados, destacam-se os dados a seguinte.

SE tinha contato muito eventual com o computador nos cursos realizados na Fundação Bradesco, apresentando dificuldade na localização de teclas. Apresentava boa noção de conhecimentos sobre navegação na internet e uso de leitor de tela, tendo clara preferência pelo Virtual Visión, o qual era oferecido pela fundação onde ela tinha contato com o do computador.

$\mathrm{SC}$ apresenta um conhecimento intermediário no uso do computador, em função da participação em diversos cursos de informática oferecidos pela Fundação Bradesco. Possui um computador em casa, mas não costuma utilizá-lo, pois ele não está devidamente configurado. SC tem boa experiência no uso do Virtual Visión, apresentando, portanto, clara preferência pelo uso desta tecnologia assistiva.

O nível de fluência digital de SK era o mais alto entre os participantes do grupo de deficientes visuais, apresentando muita independência no uso do computador e, pelos mesmos motivos de SC e SE, explicitou predileção pelo Virtual Visión. Também conseguia utilizar o computador fazendo uso de softwares aumentadores de tela, visto que apresentava visão residual.

SL é o mais velho do grupo de usuários com Síndrome de Down, tendo 31 anos e já havendo completado o ensino médio. Possui ótimo domínio do computador e muita autonomia na navegação na internet, acessando inclusive em sua casa. SL também usa o computador para conversar com os amigos via MSN, para mandar recados pelo Orkut e para preparar cartões de aniversário digitais para serem enviados para seus amigos. Tem interesse em se aperfeiçoar no uso do computador, demonstrando muita proatividade na exploração de novos softwares.

SF é uma menina com 20 anos de idade que estava concluindo o ensino médio no período em que foram coletados os dados. Ela também possui um bom domínio do uso do computador e da navegação na internet. Tem computador em casa, mas, no momento da realização deste estudo, estava sem acesso à internet por decisão de sua mãe.

O terceiro sujeito do grupo com Síndrome de Down, e o mais jovem, é SB, de 15 anos. Ele se encontrava cursando a sétima série do ensino fundamental e também apresenta um ótimo domínio no uso do computador e no acesso a internet.

Já no grupo de participantes com deficiência física, o sujeito SR tem 44 anos e vive em Córdoba. Terminou o ensino médio e possui bons conhecimentos de informática, visto que trabalhava no controle e manutenção dos computadores de uma fábrica de joias. Parou de trabalhar desde que sofreu um acidente de motocicleta, em 1997, e se tornou tetraplégico, apresentando apenas movimentos reduzidos no membro superior direito.

Para a manipulação do computador, SR utiliza a ativação de teclas especiais do Windows, como o recurso de "teclas presas", apresentadas nas opções de acessibilidade do sistema operacional. Apresenta um amplo conhecimento de teclas de atalho e de tecnologias assistivas. O sujeito também tem acesso ao computador em sua residência.

O outro membro deste grupo, SJ, tem 64 anos de idade e também vive em Córdoba. Com um histórico semelhante a SR, SJ também terminou o ensino médio e perdeu os movimentos em decorrência de um acidente de trânsito. Como decorrência, também perdeu os movimentos dos membros superiores e inferiores, apresentando movimentos em apenas um dos membros (superior esquerdo), os quais são ainda mais reduzidos em amplitude do que os apresentados por SR.

SJ possui um nível básico de conhecimento de TIC, visto que usou por algum tempo o computador em seu local de trabalho. Atualmente tem contato com a tecnologia apenas na FEPAMIC, local onde desenvolve atividades diariamente. $\mathrm{O}$ sujeito acessa a tecnologia fazendo uso de um apontador preso na mão esquerda e com o sistema operacional configurado para o uso de "teclas de presas". Como SJ não consegue manipular o mouse, ele utiliza o computador configurado para movimentar o cursor e para fazer cliques através das setas do teclado.

Para que fosse possível a realização da análise dos cenários de utilização da ferramenta tornou-se necessária a definição dos procedimentos para levantamento de informações. Nesse sentido, fez-se uso dos seguintes instrumentos para coleta de dados: registro de comentários, contemplando os comentários inseridos pelos usuários nas produções e os documentos multimídia criados; e a observação participante, mediante análise dos registros em vídeo das sessões de interações e dos apontamentos 
dos diários de campo dos mediadores, onde constavam anotações sobre os encontros realizados.

\subsection{Análise dos processos de apropriação}

A fim de realizar a análise do processo de apropriação tecnológica dos usuários frente à ferramenta aqui proposta, tornou-se fundamental o aporte teórico de Vygotsky referente ao desenvolvimento dos indivíduos mediante a interação com pares mais experientes. $\mathrm{O}$ autor formula o conceito de Zona de Desenvolvimento Proximal, assim descrito: "Ela é a distância entre o nível de desenvolvimento real, que se costuma determinar através da solução independente de problemas, e o nível de desenvolvimento potencial, determinado através da solução de problemas sob a orientação de um adulto ou em colaboração com companheiros mais capazes" [23]. O autor ainda destaca que, uma vez internalizados, esses processos tornam-se parte das aquisições do desenvolvimento independente da criança.

Gallimore e Tharp [8] destacam que o caminho percorrido pelo indivíduo através da zona de desenvolvimento proximal pode ser dividido em 4 etapas, de acordo com o nível de assistência que se faz necessário em cada momento. O primeiro estágio representa o momento em que o indivíduo consegue atingir determinada capacidade somente através da assistência de indivíduos mais capazes, que oferecem orientações e modelos ao par menos experiente. Ao final deste estágio, a assistência para a excussão da tarefa passa a ser assumida pelo próprio sujeito, atingindo-se o estágio autoassistido (estágio 2), com a transição da resolução de problemas/tarefas do plano intermental para o plano intramental. $\mathrm{O}$ terceiro estágio, da automatização, é atingido quando não há mais necessidade de assistência dos mais capazes ou autoassistência para a execução da tarefa. Por fim, tem-se o quarto e último estágio, denominado desautomatização, o qual leva a um retorno à ZDP, podendo conduzir ao desenvolvimento de novas capacidades.

A fim de analisar os aspectos relacionados à apropriação tecnológica da utilização da Oficina Multimídia, foram tomados como base os três primeiros estágios de desenvolvimento propostos por Gallimore e Tharp. Em todas as atividades propostas, foi verificado, para cada indivíduo e em cada encontro, o nível de desenvolvimento atingido. Neste sentido, foram elaborados gráficos referentes à evolução (e regresso a estágios anteriores) de cada indivíduo no decorrer dos encontros, conforme exemplificado na figura 3, e também referentes ao estágio final de desenvolvimento atingido pelo indivíduo dentro do seu grupo (Figura 4).

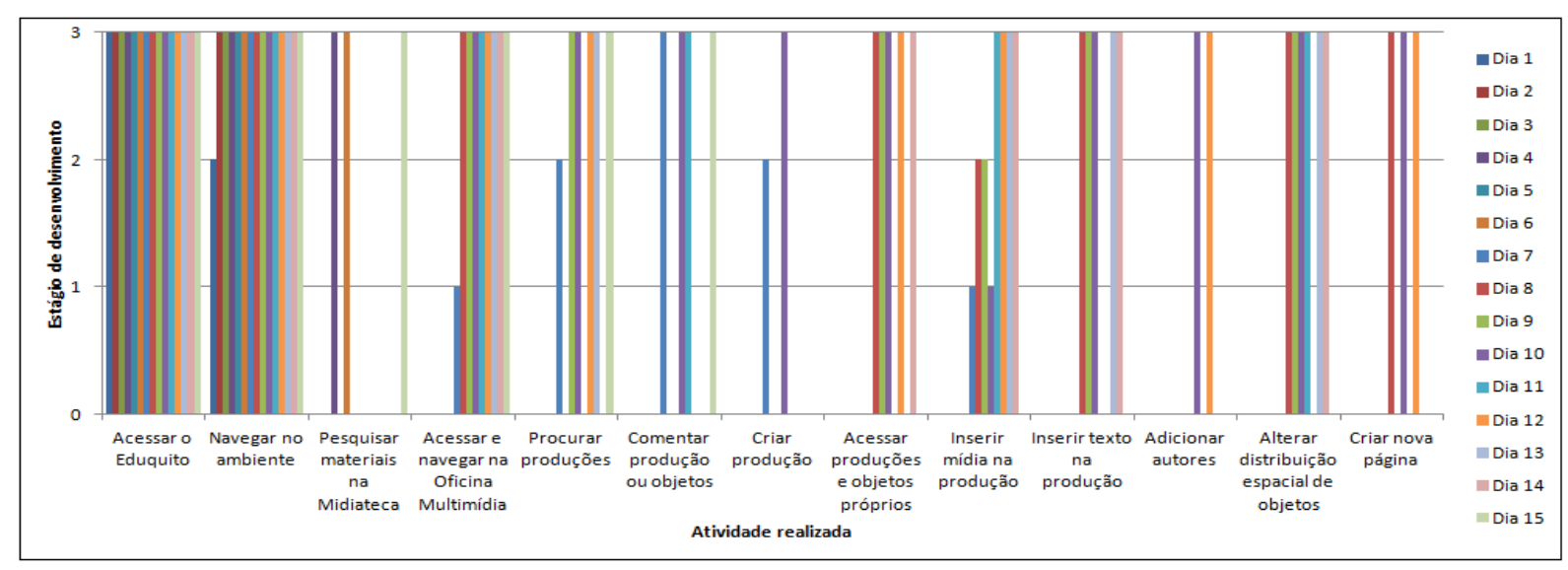

Figura 3 - Apropriação do sujeito SL no decorrer dos encontros 
Basso at al. A interação e apropriação tecnológica de pessoas com deficiência através de ferramenta multimídia acessível

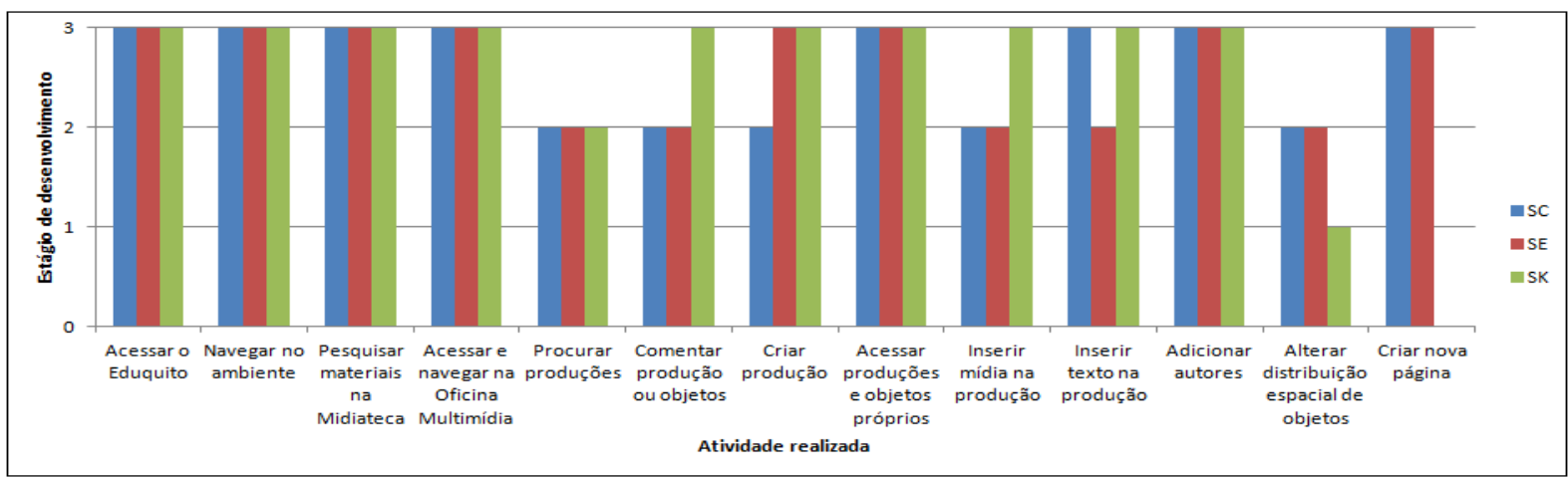

Figura 4 - Estágios finais de desenvolvimento do grupo de DV por atividade

Evidencia-se a importância de destacar que, no início da realização de novas atividades, os mediadores ofereciam informações gerais sobre os recursos a serem explorados, reproduzindo os dados que encontravam-se disponíveis na ferramenta de ajuda do sistema. O impacto da facilitação destas informações pelos mediadores deve ser considerado sobre os dados obtidos e as reflexões apresentadas a seguir.

Observou-se, no decorrer do desenvolvimento das atividades nos distintos grupos analisados, o grande potencial das trocas promovidas entre sujeitos de diferentes níveis de experiência para o processo de apropriação tecnológica daqueles que ainda não conseguem realizar determinadas tarefas sem suporte externo. Através destas interações, tornou-se possível perceber o caminho percorrido pelos participantes através da ZDP [23] e dos seus sucessivos estágios, propostos por Gallimore e Tharp [8]. A análise destas trocas também possibilitou verificar os benefícios, aos sujeitos mais experientes, decorrentes dos processos, por eles executados, durante a transmissão de instruções ou dicas para seus companheiros, conforme destacado por Morishima et al. [12]. Além de fortalecer o aspecto emocional destes indivíduos, especialmente a autoestima, mediante a valorização de suas experiências, estes indivíduos necessitavam organizar suas ideias e estruturar formas de comunicá-las, fazendo com que os seus conhecimentos adquiridos previamente fossem revistos, levando a um fortalecimento ou reestruturação durante as trocas realizadas. Destacam-se, aqui, as atuações de SR, SL, SC e SK na busca pelo compartilhamento de suas experiências com os demais colegas dos grupos.

A análise do movimento realizado pelos participantes através da ZPD, partindo do desempenho das atividades de forma assistida em direção à realização de forma autônoma, permitiu a identificação de pontos de complexidade no software proposto, bem como a validação do uso de alguns recursos que facilitaram a interação mediante a superação das limitações associadas às necessidades especiais dos participantes.

Neste sentido, salienta-se a atuação dos integrantes do grupo de DV, os quais conseguiram atingir um bom nível de apropriação da tecnologia, realizando as tarefas, por vezes, através dos caminhos alternativos oferecidos pelo sistema (uso do formulário acessível para distribuição espacial dos objetos, por exemplo). A compatibilidade da Oficina Multimídia com o software leitor de tela utilizado (NVDA) também foi outro ponto de destaque no decorrer das atividades desenvolvidas com este grupo, demonstrando a robustez do sistema ao atender ao princípio 4 (robustez) da WCAG 2.0.

O grupo de participantes com Síndrome de Down também expôs bom nível de independência no decorrer da utilização do sistema, sublinhando-se a atuação do sujeito mais experiente na prestação de assistência aos demais colegas. Neste grupo, a utilização de ícones e de cores associados à interface configurou-se como um importante recurso para facilitar a apropriação.

Já no grupo com deficiência física, pôde ser observar a maior diferença entre o grau de apropriação obtido pelos sujeitos, visto que o sujeito mais experiente conseguia realizar a maioria das atividades sem receber qualquer tipo de assistência inicial enquanto seu colega permaneceu em estágios assistidos em boa parte das tarefas. Acredita-se que a dificuldade de adaptação desse último sujeito à tecnologia assistiva de acesso ao ambiente Eduquito possa ter influenciado no resultado apontado, uma vez que ele não conseguiu interagir adequadamente com os elementos da interface humano-máquina, deixando de superar um importante degrau na escada da acessibilidade. Destacam-se os resultados dos testes realizados com este grupo referentes ao uso das tecnologias assistivas oferecidas pelo sistema operacional SIeSTA (Sistema 
Integrado de e-Servicios y Tecnologías de Apoyo), através da utilização do dispositivo iFreeTablet ${ }^{1}$. Foram testados recursos de acessibilidade tais como um sistema de varredura ativado por acionador, sistema de mouse facial e sistema de ampliação de tela, apresentando plena compatibilidade com o ambiente Eduquito, bem como gerando um relatório de melhorias neste sistema para uso por pessoas com deficiência física.

Como resultado da análise dos processos de apropriação tecnológica pelos investigados, propôs-se uma relação de problemas (ou de melhorias) identificados, bem como as respectivas soluções a serem executadas futuramente, aprimorando uma subsequente versão da Oficina Multimídia. Adicionalmente, foram definidos recursos a serem incorporados a duas novas ferramentas que estão sendo desenvolvidas atualmente pelo NIEE e que serão acopladas ao ambiente Eduquito: o Bloguito e o Quadro Branco [20]. Possibilita-se, desta forma, o aproveitamento da experiência advinda dos testes realizados na investigação aqui apresentada.

Destaca-se que, apesar de todos os esforços e critérios considerados no processo de modelagem e desenvolvimento do software, incluindo a realização dos testes de prototipação em papel, somente a realização de uma validação com sujeitos reais permitiu evidenciar certos aspectos. Ressalta-se, aqui, a importância da realização dos estudos de caso junto a grupos com as mais distintas características para a observação desses fenômenos e identificação dos problemas remanescentes.

\subsection{Análise dos processos de interação}

Tomando-se como base as trocas realizadas pelos participantes, iniciou-se a análise das questões relacionadas às interações instituídas nos processos de elaboração de materiais multimídia. Buscou-se observar o desenvolvimento de produções coletivas regidas pela colaboração ou pela cooperação. Adotou-se, para tanto, a definição de Maçada e Tijiboy [11], onde a colaboração institui uma relação de ajuda (mútua ou unilateral) na interação, ao passo que na cooperação, além de estarem presentes a interação e a colaboração, devem haver objetivos comuns, atividades e ações conjuntas/coordenadas, pressupondo relações de respeito mútuo e não hierárquicas, posturas de convivência com as diferenças, além de um contínuo processo de negociação.

Ainda baseando-se na interação dos indivíduos na construção das produções, buscou-se identificar a ocorrência de dois conceitos da tipologia proposta por Primo e Recuero [13] para os documentos produzidos: o hiper-

${ }^{1}$ Computador portátil em formato de prancheta tátil, o qual pode ser acessado diretamente com toques em sua tela. Informações complementares podem ser encontradas no website http://www.ifreetablet.es/ texto colagem, que constitui uma atividade de escrita coletiva, mas demanda mais um trabalho de administração e reunião das partes criadas em separado; e o hipertexto cooperativo, onde todos os envolvidos compartilham a invenção do texto comum, à medida que exercem e recebem impacto do grupo, do relacionamento construído e do produto criativo em andamento.

A análise das interações no desenvolvimento das produções (individuais ou coletivas) possibilitou a elaboração de gráficos, conforme exemplificado na figura 5, apontando o amplo crescimento da ocorrência de situações de negociações, críticas e sugestões entre os participantes nas atividades caracterizadas como cooperativas.

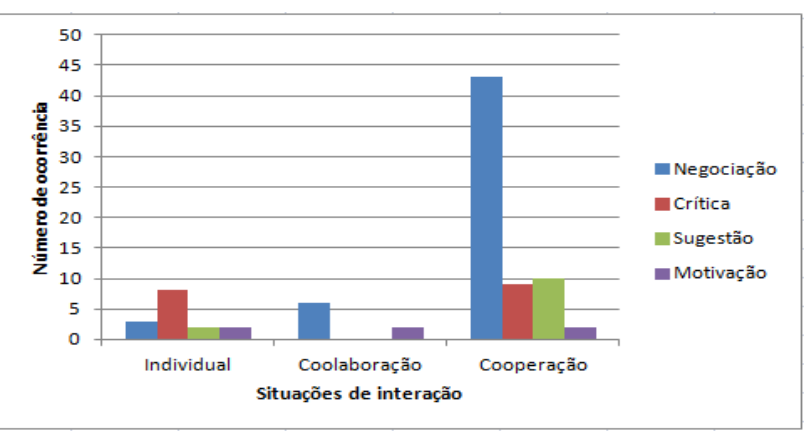

Figura 5 - Interação nas diferentes formas de produção do grupo de DV

Observou-se que o software propiciou o desenvolvimento tanto de ações de colaboração quanto de cooperação. Notou-se que as atividades de colaboração foram desenvolvidas em situações nas quais os participantes não realizaram profundos processos de negociação, procedendo com a simples concatenação de partes elaboradas em uma mesma produção. Diante desta verificação, pôdese comprovar a relação entre o processo de colaboração com o desenvolvimento de uma produção colagem. Já a cooperação foi encontrada no decorrer do desenvolvimento de duas produções coletivas (com os grupos de DV e de Downs), onde houve intensos processos de negociação, culminando na elaboração de uma produção cooperativa, isto é, em um produto compartilhado por todo o grupo e representativo do impacto das negociações presentes durante todo o seu processo de construção, conforme destacado por Primo e Recuero [13].

Constatou-se, nas produções dos três grupos, o claro predomínio do uso de signos verbais escritos, sendo os signos imagéticos estáticos o segundo tipo de mídia mais presente nas produções. Acredita-se que a complexidade no processo de download e manipulação de vídeos e músicas pelos participantes, aliado ao limite no tamanho de arquivos a serem inseridos na Midiateca (base de mídias do AVA Eduquito), foi um fato decisivo para os resultados aqui apresentados, além da facilidade na apro- 
priação da tarefa de inserção de objetos de texto, revelada previamente.

\section{Considerações finais}

Diante de um contexto em que a evolução tecnológica amplia as formas de acesso e disseminação da informação explorando o uso da multimídia e a mescla dos diferentes tipos de linguagens, percebe-se que uma parte da sociedade acaba sendo excluída desses processos de produção e consumo de dados por apresentar características muito distintas do chamado "padrão de normalidade". São justamente esses os indivíduos que podem ser mais beneficiados pelo uso das TIC, visto que, através delas, torna-se possível superar barreiras impostas pelas limitações vinculadas às características especiais desses sujeitos e potencializar as qualidades que muitas vezes permanecem escondidas atrás da cortina do preconceito. Destaca-se, portanto, a relevância do respeito à acessibilidade em ambientes de produções multimídia como uma forma de ampliar os espaços para interação e expressão das pessoas, independentemente de suas características.

A constatação da carência desse tipo de recurso tecnológico apresentado de forma acessível motivou o desenvolvimento da presente investigação, partindo da implementação da Oficina Multimídia, a qual passou a ser apresentada de forma integrada ao AVA Eduquito e às suas demais ferramentas. Observou-se o alinhamento do protótipo aos princípios de acessibilidade, notando-se, no entanto, a possibilidade de efetuar pequenas alterações para obter maior adequação às sugestões da WAI/W3C.

A validação da ferramenta proposta com grupos de distintas características (deficientes visuais, portadores de Síndrome de Down e deficientes motores), possibilitou a análise da apropriação tecnológica através do movimento realizado pelos participantes através da ZDP, partindo do desempenho das atividades de forma assistida em direção à realização de forma autônoma. Este movimento permitiu a identificação de pontos de complexidade no software proposto, bem como a validação do uso de alguns recursos que facilitaram a interação mediante a superação das limitações associadas às necessidades especiais dos participantes. Tais recursos serão incorporados a duas novas ferramentas que estão sendo desenvolvidas atualmente pelo NIEE, possibilitando o aproveitamento da experiência advinda dos testes realizados na presente investigação.

Observou-se que o software propiciou o desenvolvimento de ações de colaboração e de cooperação. Atividades de colaboração ocorreram em situações em que os participantes procederam com a simples concatenação de partes de uma mesma produção, instituindo uma relação entre o processo de colaboração e o desenvolvimento de produção colagem. Já a cooperação foi encontrada em produções onde houve intensos processos de negociação, culminando em uma produção cooperativa, isto é, representativa das negociações presentes durante seu processo de construção.

Conclui-se que o recurso estudado atingiu seu objetivo de estabelecer-se como uma alternativa acessível para o desenvolvimento de materiais multimídia, seja de forma individual ou coletiva, favorecendo a participação e a expressão de pessoas com deficiência. A inclusão propiciada pela abertura de um espaço desenvolvido com tecnologias gratuitas (software livre) que permite "ouvir as vozes" desses sujeitos pôde ser percebida nas produções desenvolvidas pelos próprios participantes da investigação.

\section{Referências}

[1] C. M. M. C. Alonso; C. B. Rizzi; L. M. J. Seixas. Software Equitext - Uma ferramenta para escrita colaborativa na web. In: Taller Internacional de Software Educativo, Santiago. Anales. 2003.

[2] M. Axt, A. Martins. EccoLogos: autoria coletiva de documentos. Revista Informática na Educação: Teoria e Prática, 7(2): 39-49, 2004.

[3] L. O. Basso, Ferramenta acessível para produção multimídia: estudo e avaliação com usuários com necessidades especiais. Tese de Doutorado Em Informática na Educação, Universidade Federal do Rio Grande do Sul, fev. 2012.

[4] L. O. Basso, J. F. P. Cheiran, L. M. C. Santarosa. Desafios no uso de prototipação em papel com PNEs para definição de interfaces de editor de documentos multimídia. In: Anais do XX Simpósio Brasileiro de Informática na Educação, Florianópolis, 2009.

[5] P. A. Behar; A. L. Macedo; J. Bitencort; B. Mazzocato. Escrita Coletiva: o potencial de um Groupware via Web. Revista Novas Tecnologias na Educação, 4(1), 2006.

[6] M. A. F. Borges. Um processo para a análise da interação em sistemas colaborativos mediados por ferramentas computacionais para comunicação textual. Tese de Doutorado em Ciência da Computação, Universidade Estadual de Campinas, 2004.

[7] A. Cockburn, J. Highsmith. Agile Software Development: The People Factor. IEEE Computer, 
131-133, nov. 2001.

[8] R. Gallimore, R. Tharp. O pensamento educativo na sociedade: ensino, escolarização e discurso escrito. In: Moll, L. C. Vygotsky e a educação: implicações pedagógicas da psicologia sóciohistórica. Artes Médicas, Porto Alegre, 1996.

[9] D. Haetinger; I. Abegg; J. Costa; L. M. R. Tarouco; M. Foohs; F. Santos; M. Schmitt; R. Ruduit; V. Lindemann. TWiki, uma ferramenta de co-autoria livre. Revista Novas Tecnologias na Educação, 3(2), nov. 2005.

[10] J. Highsmith, A. Cockburn. Agile Software Development: The Business of Innovation. IEEE Computer, 120-122, set. 2001.

[11] D. L. Maçada, A. V. Tijiboy. A Colaboração e Cooperação via Internet nas Organizações. In: Encontro da ENAMPAD, 21, 1997.

[12] Y. Morishima, H. Nakajima, S. Brave et al. The Role of Affect and Sociality in the Agent-Based Collaborative Learning System. In: E. André, L. Dybkjaer, W. Minker. Affective Dialog Systems: Tutorial and Research Workshop. Springer, New York, 265-275, 2004.

[13] A. F. T. Primo, R. C. Recuero. Hipertexto Cooperativo: Uma Análise da Escrita Coletiva a partir dos Blogs e da Wikipédia. Revista da Famecos, 23: 54-63, dez. 2003.

[14] A. F. T. Primo; R. P. Rocha; M. Träsel; L. O. Basso; R. M. Araújo. A escrita coletiva de hipertextos com links multidirecionais através do CoLink Wiki em processos educacionais. In: Simpósio Brasileiro de Informática na Educação, $16,2005$.

[15] A. C. Piconi; E. H. Tanaka. O Uso do HagáQuê Por Alunos Autistas. In: Congreso Iberoamericano de Informática Educativa Especial (CIIEE), 3., 2002.

[16] L. Santaella. Linguagens líquidas na era da mobilidade. Paulus, São Paulo, 2007.

[17] L. M. C. Santarosa; A. Ortolan; L. O. Barrionuevo; R. Puhl; E. Burmeister; K. Paul. Fábrica Fantástica: Ambiente Hipermídia Lúdico para o Desenvolvimento Cognitivo. In: Congreso Iberoamericano de Informática Educativa, 3. 1996.

[18] L. M. C. Santarosa, L. O. Basso. Oficina de Produção: uma ferramenta de escrita coletiva de documentos. In: Revista Novas Tecnologias na Educação, 6: 1-10, 2008.
[19] L. M. C. Santarosa, L. O. Basso. Eduquito: Virtual Environment for Digital Inclusion of People with Special Educational Needs. In: Journal of Universal Computer Science, 15: 1496-1507, 2009.

[20] L. M. C. Santarosa, D. Conforto, L. O. Basso Ferramentas de autoria e de colaboração: discutindo a acessibilidade e a usabilidade na perspectiva da Web 2.0". In: Simpósio Brasileiro de Informática na Educação, 22., 2011.

[21] P. Schäfer; R. Lacerda; L. C. Fagundes. Escrita colaborativa na cultura digital: ferramentas e possibilidades de construção do conhecimento em rede. Revista Novas Tecnologias na Educação, 7(1), jul. 2009.

[22] A. P. Sonza. Ambientes virtuais acessíveis sob a Perspectiva de Usuários com Limitação Visual. Tese de Doutorado em Informática na Educação, Universidade Federal do Rio Grande do Sul, 2008

[23] L. S. Vygotsky. A formação social da mente: o desenvolvimento dos processos psicológicos superiores. Martins Fontes, São Paulo, 2007. 